\title{
A Case of HELLP Syndrome with Multiple Complications
}

\author{
Yoshiaki Iwashita, Tomomichi Kan'o, Jun Hattori, Shingo Konno, Hiroshi Imai, \\ Takao Kitahara and Kazui Soma
}

\begin{abstract}
Hemolysis, elevated liver enzymes, and low platelet (HELLP) syndrome is a rare complication of pregnancy. The mortality rate associated with HELLP syndrome increases when life-threatening complications occur. A 37-year-old woman at 37 weeks of gestation developed severe cerebral hemorrhage at the beginning of labor induction and was transferred to our hospital, where HELLP syndrome was diagnosed. She developed disseminated intravascular coagulation (DIC), hepatic hematoma, and cerebral infarction after surgery. On day 68, she was transferred to her local hospital. Careful observation and rapid management can save patients with severe complications of HELLP syndrome.
\end{abstract}

Key words: cerebral hemorrhage, DIC, liver hematoma, pregnancy

(Intern Med 51: 2227-2230, 2012)

(DOI: 10.2169/internalmedicine.51.7715)

\section{Introduction}

HELLP syndrome occurs in $0.5 \%$ to $0.9 \%$ of all pregnancies, with a reported mortality rate of $1.1 \%$ (1). Despite the relatively low mortality rate associated with HELLP syndrome, life-threatening complications, including DIC, cerebral hemorrhage, and hepatic hematoma have been reported. Each of these potential complications is well described, but to our knowledge, no previous case of HELLP syndrome has manifested multiple complications. Here we present a case of HELLP syndrome that was complicated by concurrent DIC, cerebral hemorrhage, and hepatic hematoma.

\section{Case Report}

A 37-year-old woman (gravida, 2; para, 1) was admitted to a nearby hospital at 37 weeks of gestation for induction of labor. Her past medical history had been unremarkable until proteinuria was noted at 2 days prior to admission. At the onset of labor, she began complaining of severe headache and lost consciousness. Computed tomography (CT) revealed right frontal subcortical cerebral hemorrhage with intraventricular and subarachnoid bleeding (Fig. 1). The patient was transferred to our hospital, where physical examination revealed a Glasgow Coma Scale (GCS) of E1V1M2, pupil sizes of $3 \mathrm{~mm}$ (right) and $1 \mathrm{~mm}$ (left), bilaterally negative light reflex, and blood pressure of 220/120 $\mathrm{mmHg}$. The fetal heart rate was 150 beats per minute.

Serum tests showed total bilirubin of $1.2 \mathrm{mg} / \mathrm{dL}$, lactate dehydrogenase of $1,895 \mathrm{IU} / \mathrm{L}$, serum aspartate aminotransferase of $562 \mathrm{IU} / \mathrm{L}$, serum alanine aminotransferase of 461 IU/L and platelet count of $133,000 / \mathrm{m}^{3}$. These findings suggested HELLP syndrome. Diltiazem $10 \mu \mathrm{g} / \mathrm{kg} / \mathrm{min}$ was begun to lower the patient's blood pressure. As her blood pressure decreased, the fetal heart rate also began to decrease to a minimum of 70 beats per minute. At this point, diltiazem was stopped and the patient was transferred to the operating room for Caesarean section; the infant had APGAR scores of 5 and 6 after 1 and 5 minutes, respectively, and was transferred to the neonatal intensive care unit. The infant stabilized soon thereafter and was released. The mother subsequently underwent craniotomy and hematoma evacuation. After surgery, the GCS was still E1V1M2, and blood tests showed decreased liver enzymes, decreased platelets, and prolonged coagulation time, indicative of DIC.

The day after surgery (day 2 of hospitalization), although the platelet count and coagulation values had returned to normal, the hepatic enzymes increased sharply again. Abdominal contrast-enhanced CT revealed a hepatic subcapsular hematoma (Fig. 2). Because no extravasation was present, a conservative course of observation only was elected. 


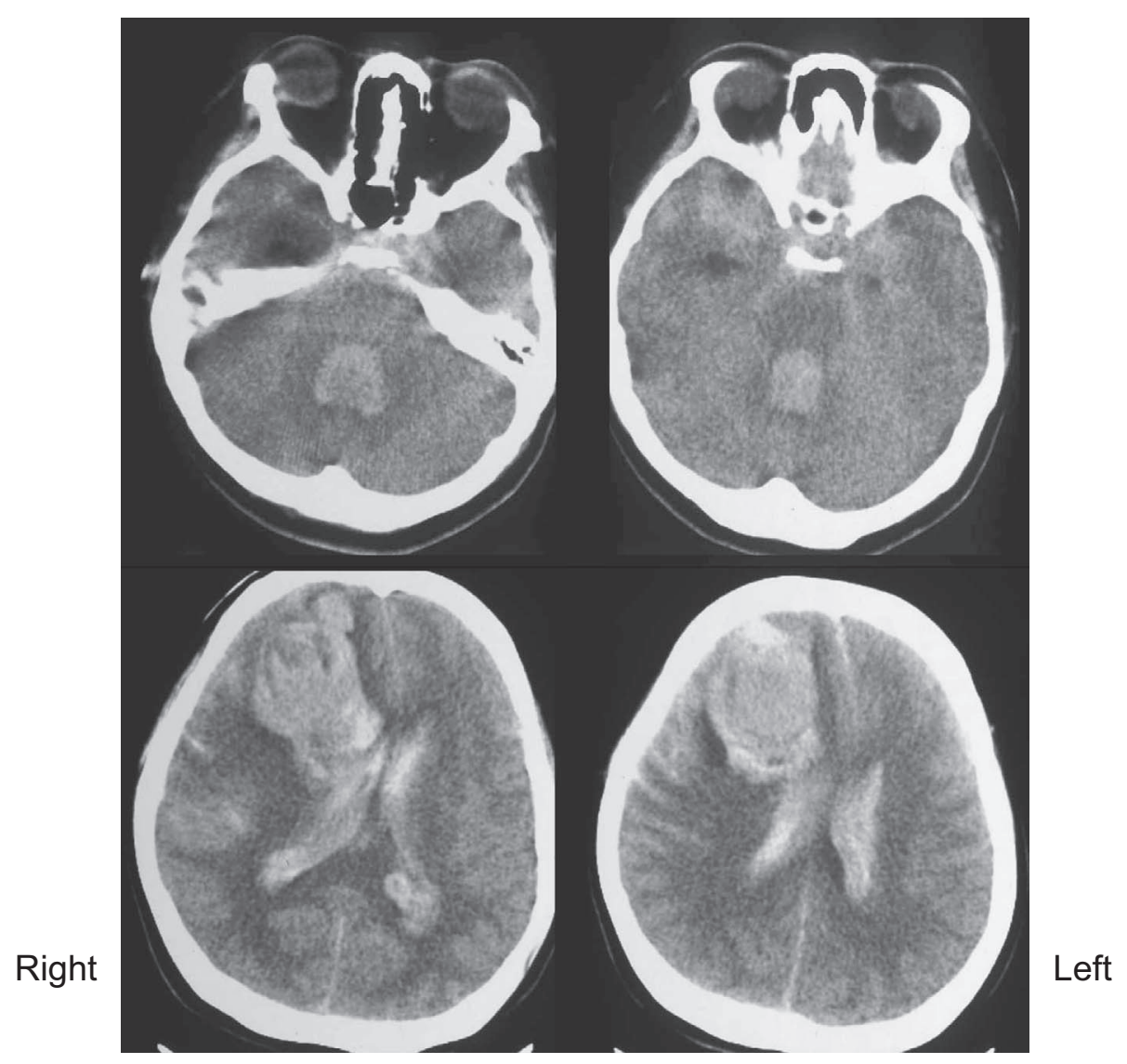

Figure 1. Head CT on day 1. CT imaging revealed cerebral hemorrhage in the right frontal lobe. In addition, hematomas are present in the cerebral ventricle and subarachnoid space.
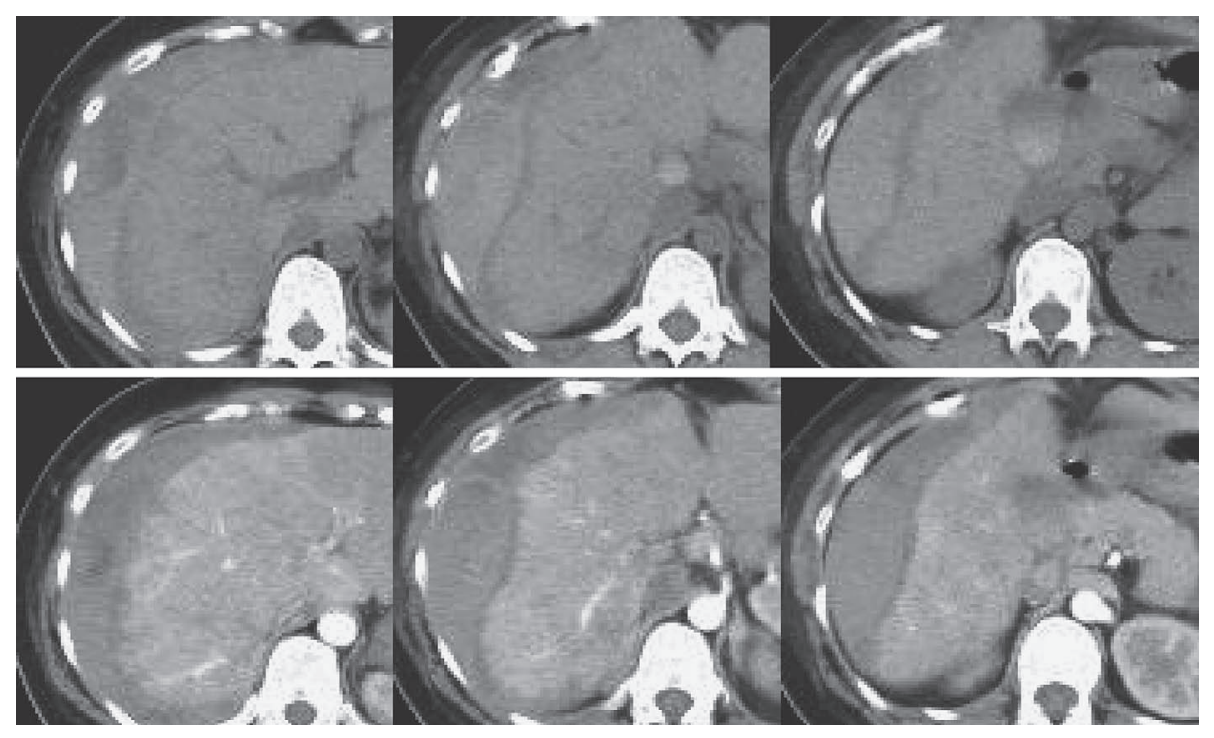

Figure 2. Abdominal CT on day 2. CT examination of the patient's abdomen revealed a subcapsular hepatic hematoma as a high-density area on noncontrast-enhanced imaging. Early-phase contrast-enhanced CT showed no extravasation.

Liver enzymes began to decrease on day 3 of hospitalization and returned to normal on day 19. On day 18 , she remained anisocoric, with no other neurologic deficits. Repeat CT revealed multiple cerebral infarctions (Fig. 3), which we surmise to have resulted from vasospasm after subarachnoid hemorrhage. Because her level of consciousness was still
GCS E1V1M2, no treatment other than observation was performed.

Her level of consciousness gradually increased, cranioplasty and ventriculoperitoneal shunting were performed on days 38 and 48, respectively. The patient began to speak on day 68 (GCS E4V5M6), when she was transferred to an- 


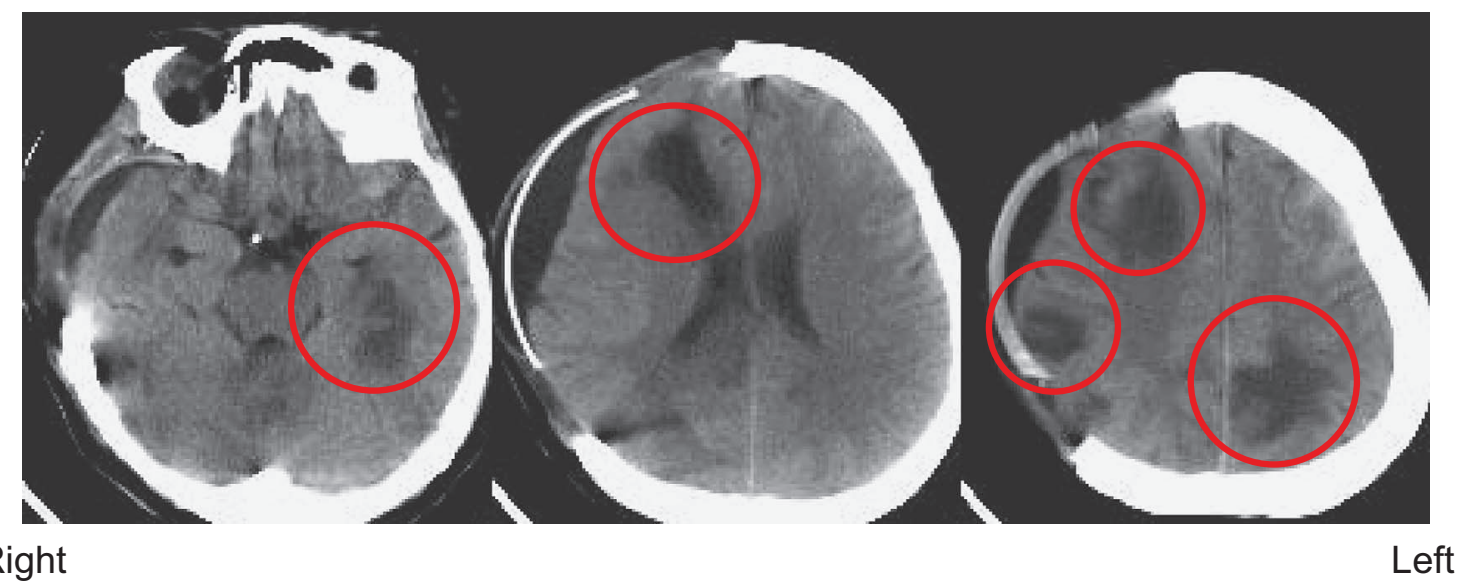

Figure 3. Head CT on day 18. Multiple cerebral infarctions (red circles) are present, probably due to vasospasm secondary to subarachnoid hemorrhage.

other hospital for further rehabilitation.

\section{Discussion}

Although the etiology underlying HELLP syndrome is unclear, endothelial cell injury with increased activation of the coagulation system is proposed to play a contributing role. This condition may predispose patients to various additional complications.

DIC is one of the most frequent complications of HELLP syndrome and occurs in $15 \%$ to $20 \%$ of patients with this condition $(2,3)$. We surmise that endothelial injury due to abnormal placentation and resulting placental ischemia led to DIC in the current case. Coagulation abnormalities often resolve once pregnancy is no longer present. Consistent with this reported pattern, the coagulopathy and thrombocytopenia in the present patient had resolved by the day after delivery.

Intracranial hemorrhage is rare but potentially lethal complication that occurs in $1.5 \%$ of patients with HELLP syndrome, and $45 \%$ of maternal deaths due to HELLP syndrome are associated with intracranial hemorrhage $(3,4)$. The type of intracranial hemorrhage that can develop varies and includes cerebral hemorrhage, pontine hemorrhage, and subdural hematoma (5-10). The present patient suffered a large hemorrhage that spanned from the right frontal lobe to the cerebral ventricle and subarachnoid space. Some cases of cerebral hemorrhage during pregnancy may be due to preeclampsia-induced vasospasm, which may occur because of increases in vasoconstrictive agents, such as thromboxane A2 (10). We surmise that the subarachnoid bleeding in the present patient led to subsequent vasospasm and progression to multiple areas of infarction. Craniotomy prevented further increases in intracranial pressure in our patient, thus helping to improve her neurologic outcome.

Liver hematoma is a well-described complication among patients with HELLP syndrome and it can vary in severity from hepatic rupture requiring emergent surgery to a small hematoma that resolves spontaneously after observation only (11-13). Most hemodynamically stable patients respond successfully to conservative treatment (observation only). However, once a hepatic hematoma ruptures, mortality increases to $86 \%$ (1). Several considerations are involved in the management of hepatic hematoma (14). In managing the present patient's condition, we consulted a vascular surgeon, prepared blood products, avoided direct and indirect manipulation of the liver, and closely monitored her hemodynamic status. Ultimately she recovered without the need for hepatic surgery or provision of blood products.

\section{Conclusion}

The present patient experienced three rare but lifethreatening complications of HELLP syndrome: DIC, cerebral hemorrhage, and liver hematoma. Although each can have serious consequences, careful observation and prompt treatment can lead to a successful outcome. It is crucially important to aggressively monitor patients with HELLP syndrome for the development and progression of complicating conditions.

The authors state that they have no Conflict of Interest (COI).

\section{References}

1. Haram K, Svendsen E, Abildgaard U. The HELLP syndrome: clinical issues and management. A review. BMC Pregnancy Childbirth 9: 8, 2009.

2. Sibai B, Mohammed R, Usta I, Salama M, Mercer B, Friedman S. Maternal morbidity and mortality in 442 pregnancies with hemolysis, elevated liver enzymes, and low platelets (HELLP syndrome). Am J Obstet Gynecol 169: 1000-1006, 1993.

3. Audibert F, Friedman S, Frangieh A, Sibai B. Clinical utility of strict diagnostic criteria for the HELLP syndrome. Am J Obstet Gynecol 175: 460-464, 1996.

4. Isler C, Rinehart B, Terrone D, Martin R, Magann E, Martin J. Maternal mortality associated with HELLP syndrome. Am J Obstet Gynecol 181: 924-928, 1999.

5. Knopp U, Kehler U, Rickmann H, Arnold H, Gliemroth J. Cerebral hemodynamic pathologies in HELLP syndrome. Clin Neurol 
Neurosurg 105: 256-261, 2003.

6. Hashiguchi $\mathrm{K}$, Inamura $\mathrm{T}$, Irita $\mathrm{K}$, et al. Late occurrence of diffuse cerebral swelling after intracerebral hemorrhage in a patient with the HELLP syndrome. Neurol Med Chir 41: 144-148, 2001.

7. Altamura C, Vasapollo B, Tibuzzi F, et al. Postpartum cerebellar infarction and hemolysis, elevated liver enzymes, low platelet (HELLP) syndrome. Neurol Sci 26: 40-42, 2005.

8. Yokota H, Miyamoto K, Yokoyama K, Noguchi H, Uyama K, Oku M. Spontaneous acute hematoma and intracerebral hemorrhage in patient with HELLP syndrome: case report. Acta Neurochir 151: 1689-1692, 2009.

9. Zeidman L, Videnovic A, Bernstein L, Peller C. Lethal pontine hemorrhage in postpartum syndrome of hemolysis, elevated liver enzyme levels, and low platelet count. Arch Neurol 62: 1150$1153,2005$.

10. Gliemroth J, Knop U, Kehler U, Felberbaum R, Nowak G.
HELLP syndrome with hemoglobin vasospasm. J Clin Neurosci 7: 59-62, 2000.

11. Aldemir M, Bac Bilsel, Tacyildiz I, Yagmur Y, Keles C. Spontaneous liver hematoma and a hepatic rupture in HELLP syndrome: report of two cases. Surg Today 32: 450-453, 2002.

12. Miguelote R, Costa V, Vivas J, Gonzaga L, Menezes C. Postpartum spontaneous rupture of a liver hematoma associated with preeclampsia and HELLP syndrome. Arch Gynecol Obstet 279: 923-926, 2009.

13. Salvatore D, Giampiero C, Paolo V, et al. Hepatic rupture after caesarean section in a patient with HELLP syndrome: a case report and review of the literature. Arch Gynecol Obstet 276: 189192, 2007.

14. Barton J, Sibai B. Diagnosis and management of hemolysis, elevated liver enzymes, and low platelets syndrome. Clin Perinatol 31: 807-833, 2004.

(C) 2012 The Japanese Society of Internal Medicine http://www.naika.or.jp/imonline/index.html 